\title{
Interaction of Sulfonamide and Sulfone Compounds with Toxoplasma gondii Dihydropteroate Synthase
}

\author{
Carmen J. Allegra, * Donna Boarman, ${ }^{\star}$ Joseph A. Kovacs, ${ }^{\ddagger}$ Paul Morrison, ${ }^{5}$ Jacqueline Beaver,” \\ Bruce A. Chabner," and Henry Masur* \\ ${ }^{*}$ Medicine Branch, National Cancer Institute, ${ }^{\ddagger}$ Clinical Center, and ${ }^{\S}$ Biomedical Engineering and Instrumentation Branch, \\ Division of Research Services, National Institutes of Health, Bethesda, Maryland 20892
}

\begin{abstract}
Toxoplasma gondii is a common protozoan disease that often causes life-threatening disease, particularly among patients with the acquired immunodeficiency syndrome. This study demonstrates that the dihydropteroate synthase in $T$. gondii is kinetically distinct from the enzyme characterized from other sources and can be highly purified with a high yield using sequential dye-affinity chromatography. Conditions have been identified that allow for stabilization of the purified enzyme, and its physical characteristics have been elucidated. The molecular weight of the native protein was 125,000 and the protein appeared to contain both dihydropteroate synthase and 6-hydroxymethyl-dihydropterin pyrophosphokinase activities. The sulfonamide class of compounds vary in inhibitory potency by more than three orders of magnitude. Sulfathiazole, sulfamethoxazole, and sulfamethazine, with $50 \%$ inhibitory concentrations ( $\mathrm{IC}_{50}$ 's) of $1.7,2.7$, and $5.7 \mu \mathrm{M}$, respectively, represent the most potent of this class of inhibitors. Several sulfone analogues, including dapsone, were identified as highly potent inhibitors with $\mathrm{IC}_{50}$ 's $<1 \mu \mathrm{M}$. The results of these cell-free experiments were corroborated by investigating the metabolic inhibition produced by the various inhibitors in intact organisms. The qualitative and quantitative relations among the inhibitors were preserved in both the cell-free and intact cell assay systems. These studies suggest that the sulfones may be important therapeutic agents for the treatment of toxoplasmosis. (J. Clin. Invest. 1990. 85:371-379.) antimetabolites • enzymology $\bullet$ protozoan $\bullet$ sulfonamides
\end{abstract}

\section{Introduction}

Toxoplasma gondii infects up to $40 \%$ of individuals in North America (1). In immunocompetent patients, T. gondii exposure can result in a febrile lymphadenopathic syndrome, although most acutely infected adults are asymptomatic $(1,2)$. Fetal infection with $T$. gondii can occur in women who become infected during pregnancy, and may be accompanied by serious sequelae including neurologic abnormalities (1). $T$. gondii infection is prevalent in immunocompromised patients, particularly those with AIDS. Clinical disease occurs in $5-10 \%$ of all patients with AIDS and in $\sim 30 \%$ of toxoplasma

Address correspondence to Dr. Carmen J. Allegra, National Cancer Institute, National Institutes of Health, Building 10, Room 12N226, Bethesda, MD 20892

Received for publication 10 July 1989 and in revised form 6 October 1989.

The Journal of Clinical Investigation, Inc.

Volume 85, February 1990, 371-379 antibody-positive AIDS patients in the United States (1). If the adult who has $T$. gondii cysts has diminished function of $\mathrm{T}$ lymphocytes, especially due to AIDS, fatal disseminated disease or cerebral disease can occur.

Folate compounds are essential cofactors for a number of critical metabolic steps including the formation of purines and thymidine nucleotides. Dihydrofolate reductase (DHFR) ${ }^{1}$ is the enzyme responsible for the maintenance of folate pools in their physiologic reduced states. Dihydropteroate synthase (DHPS) is one of the enzymes responsible for the de novo synthesis of the folate molecule. Unlike mammalian cells, which possess a carrier-mediated active transport system responsible for the uptake of performed folates, $T$. gondii lack this system and must synthesize their required folates de novo (3). Several of the enzymes of the de novo folate pathway, including DHPS, are unique to nonmammalian cells, and as such provide targets for drug therapy with a potentially high therapeutic index. Therapy of $T$. gondii disease has traditionally depended on a combination of pyrimethamine, a DHFR inhibitor, and sulfadiazine, an inhibitor of DHPS. In general, DHFR and DHPS inhibitors are most effective when used in combination (4). While combination therapy is effective, the incidence of adverse side-effects in the AIDS population is substantial $(30-70 \%)(5,6)$. Due to the severity of side-effects, this therapy must be discontinued in a large percentage of patients. Clearly, alternative therapy is urgently needed.

A limited number of sulfonamide and sulfone compounds have been tested for antitoxoplasma activity in the murine animal model. Sabin and Warren initially demonstrated the utility of these compounds for the treatment of murine toxoplasmosis (7). These studies were subsequently confirmed by several independent laboratories (8-13). The classic works of Eyles and Coleman assessed the relative in vivo potency of various sulfonamide inhibitors against $T$. gondii and found sulfapyrazine, sulfamethazine, sulfamerazine, and sulfadiazine to be the most potent of the sulfonamides tested, and approximately equivalent in their ability to prolong the survival of infected mice (9-12). Notably, sulfisoxazole and sulfanilamide were found to be $\sim 20$ times less capable of prolonging survival. Subsequent studies from these same laboratories demonstrated the relative activity of several sulfone analogues, including 4,4'-diaminodiphenyl sulfone (dapsone) (13). They found dapsone to be equivalent in activity to sulfadiazine and the most potent of the tested sulfones.

Based on the effectiveness of antifolate therapy and the presumption that many of the side-effects are dose- and inhibi-

1. Abbreviations used in this paper: DHFR, dihydrofolate reductase; DHPS, dihydropteroate synthase; $\mathrm{H}_{2} \mathrm{PtCH}{ }_{2} \mathrm{OPP}$, 6-hydroxymethy7,8-dihydropterin pyrophosphate; 2-ME, 2-mercaptoethanol; pABA, paraaminobenzoate; $\mathrm{Pi}$, isoelectric focusing point. 
tor specific, we initiated an investigation of alternate DHPS inhibitors. Previous studies from our laboratory have indicated that the interaction of inhibitors with folate-dependent enzymes isolated from $T$. gondii, such as DHFR, may vary by several orders of magnitude when compared with the interactions of comparable enzymes isolated from other nonmammalian sources (4). Thus, we felt it critical to investigate the interaction of DHPS inhibitors with the target enzyme specifically isolated from the $T$. gondii organisms to guide the development of new therapies for this infection. To this end, we have developed techniques to isolate, purify, and characterize the DHPS of $T$. gondii. Further, we investigated the interaction of various DHPS inhibitors with the cell-free target enzyme and with intact $T$. gondii organisms using the metabolic activity of the organisms as a measure of drug activity.

\section{Methods}

\section{Materials}

6-Hydroxymethyl-7,8-dihydropterin pyrophosphate $\left(\mathrm{H}_{2} \mathrm{PtCH}_{2} \mathrm{OPP}\right)$ was obtained from the Drug Synthesis and Chemistry Branch, National Cancer Institute, National Institutes of Health (Bethesda, MD). The compound was synthesized according to the method of Shiota et al. (14) and the structure was confirmed by mass spectroscopy and nuclear magnetic resonance spectroscopy. The purity of the product was determined to be $82 \%$ by HPLC and was used without further purification. The HPLC method consisted of the development of a C-8 $\mu$ bondapak column with a concave gradient (No. 8) of methanol from 0 to $40 \%$ with Pic A, pH 5.5, constituting the balance of the mobile phase. The gradient was run over $40 \mathrm{~min}$ at a flow rate of 2 $\mathrm{ml} / \mathrm{min}$. Under these conditions, the $\mathrm{H}_{2} \mathrm{PtCH}_{2} \mathrm{OPP}$ substrate had a retention time of $9 \mathrm{~min}$ and was easily separable from the monophosphate (retention time $=\mathbf{4} \mathrm{min}$ ). The compound was stored as a powder under nitrogen at $-80^{\circ} \mathrm{C}$ and found to be stable for at least one year. The starting compounds for the synthesis of $\mathrm{H}_{2} \mathrm{PtCH}_{2} \mathrm{OPP}$, pyrophosphoric acid and 6-hydroxymethyl-pterin, were supplied by Fluka Biochemicals (Buchs, Switzerland) and Schiricks Laboratories (Jona, Switzerland), respectively. $3^{\prime}, 5^{\prime}-\left[{ }^{3} \mathrm{H}\right]$ Paraaminobenzoate (pABA) (sp act $50 \mathrm{Ci} / \mathrm{mmol}$ ) was purchased from Moravek Biochemicals (Brea, CA) and was found to be $>98 \%$ pure by HPLC (see below). ATP, DTT, BSA, fraction V, 2-mercaptoethanol (2-ME), and various sulfonamides including sulfabenzamide, sulfacetamide, sulfadiazine, sulfamerazine, sulfamethazine, sulfapyridine, and sulfathiazole were obtained from Sigma Chemical Co. (St. Louis, MO). 3MM paper was purchased from Whatman Laboratory Products Inc. (Clifton, NJ). Matrix gel blue A and matrix gel green A were obtained from Amicon Corp. (Lexington, MA). A protein assay kit was obtained from BioRad Laboratories (Richmond, CA). Other sulfonamide compounds were obtained from Hoffman-La Roche Inc. (Nutley, NJ), including sulfamethoxazole, sulfisoxazole, and sulfadoxine. Sulfanilamide, sulfinpyrazone, and sulfamethizole were obtained from Lilly Research laboratories, Ciba-Geigy (Suffern, NY) and Ayerst Laboratories (New York, NY), respectively. 4,4'-Diaminodiphenyl sulfone (Dapsone) was obtained from Jacobus Pharmaceutical Co. (Princeton, NJ). All other sulfone analogues were obtained from Warner-Lambert/Parke-Davis Inc. (Ann Arbor, MI) or from the Drug Synthesis and Chemistry Branch, National Cancer Institute, National Institutes of Health. Partially purified Escherichia coli DHPS was a generous gift from Dr. Robert Ferone (Burroughs-Wellcome Co., Research Triangle Park, NC).

\section{Enzyme source and purification}

$T$. gondii organisms (RH strain) were passaged every 3-4 d in the peritoneal cavities of Balb/c mice. Tachyzoites were isolated from the peritoneal exudates of 30-40 infected mice and separated from inflammatory cells by differential centrifugation as previously described (4).
The sedimented toxoplasma organisms were then resuspended in $1 \mathrm{ml}$ of PBS and either used immediately or frozen at $-80^{\circ} \mathrm{C}$.

\section{Extraction}

Preparations of $T$. gondii trophozoites were disrupted by a 60 -s burst from a Branson sonifier 350 (Branson Sonic Power Co., Danbury, CT) equipped with a microtip, and the supernatant was clarified by centrifugation $\left(4^{\circ} \mathrm{C}\right)$ at $2,000 \mathrm{~g}$ for $15 \mathrm{~min}$.

\section{Affinity chromatography}

DHPS was purified by the sequential use of two dye affinity resins, blue and green Sepharose. The enzyme-containing cytosolic supernatant was first applied at room temperature to a $0.7 \times 4-\mathrm{cm}$ glass column (Bio-Rad Laboratories) containing blue Sepharose that had been preequilibrated with $100 \mathrm{mM}$ potassium chloride $(\mathrm{KCl})$. After loading, the column was washed with $3 \mathrm{ml}$ of $100 \mathrm{mM} \mathrm{KCl}$ followed by $2 \mathrm{ml}$ of 200 $\mathrm{mM} \mathrm{KCl}$. DHPS activity was then eluted from the column with a linear gradient of $\mathrm{KCl}$ from 0.2 to $1 \mathrm{M}$. 1.2-ml fractions were collected in glass tubes $(12 \times 75 \mathrm{~mm})$ containing $10 \mathrm{mM}$ Tris/ $\mathrm{HCl}, \mathrm{pH} 8.3,5$ $\mathrm{mM}$ DTT, and $5 \mathrm{mM}$ 2-ME in $120 \mu \mathrm{l}$. These fractions were collected on ice and then assayed for DHPS activity. The fractions containing DHPS activity were pooled and concentrated by ultrafiltration using an ultrafiltration cell (Amicon Corp.) equipped with a 30,000-mol wt cut-off membrane (PM-30; Amicon Corp.). The pooled fractions were concentrated 10 -fold at $4^{\circ} \mathrm{C}$ then diluted with $40 \mathrm{mM}$ Tris/ $\mathrm{HCl}$, pH 8.3 , to yield a final salt concentration $<200 \mathrm{mM}$. The concentrated preparation was then loaded onto a second affinity column containing green Sepharose prepared in an identical fashion as the blue dye column. Elution of the DHPS activity was carried out as described above. The active fractions were again pooled and concentrated 10 -fold by ultrafiltration. The purified enzyme was stored at $-80^{\circ} \mathrm{C}$.

\section{Molecular weight determination}

Column chromatography. Purified DHPS preparations were applied to a protein sizing column (TSK 2000 SW; Beckman Instruments, Inc., Palo Alto, CA) having a usable molecular weight range of 12,000 300,000 . Protein standards including glutamate dehydrogenase $(290,000)$, lactate dehydrogenase $(142,000)$, bovine albumin $(67,000)$, and adenylate kinase $(32,000)$ were used to calibrate the column (United States Biochemical Corp., Cleveland, $\mathrm{OH}$ ). Column elution was accomplished using an HPLC (LKB-Bromma, Uppsala, Sweden) composed of a model 2150 pump, 2152 system controller, and model 2211 fraction collector. The column was developed using a flow rate of $0.3 \mathrm{ml} / \mathrm{min}$ of PBS (pH 7.0) under isocratic conditions. 0.3-ml fractions were collected at $4^{\circ} \mathrm{C}$ in glass tubes containing $10 \mathrm{mM}$ Tris/ $\mathrm{HCl}$, pH 8.3, 5 mM DTT, and $5 \mathrm{mM}$ 2-ME. The molecular weight was determined by comparison of the retention time with standards.

Gel electrophoresis. $\mathrm{NaDodSO}_{4}$ gel electrophoresis was carried out on $10 \%$ gels according to the methods of Weber et al. (15) using myosin $(200,000)$, phosphorylase b $(92,500)$, BSA $(68,000)$, ovalbumin $(43,000)$, and å-chymotrypsinogen $(25,700)$ as molecular weight standards. Protein bands were detected using a silver staining kit (Bio-Rad Laboratories).

\section{Isoelectric focusing}

Ampholine pagplates, pH 3.5-9.5 (LKB-Bromma), were used with a Multiphor apparatus (LKB-Bromma) to determine the isoelectric focusing point $(\mathrm{Pi})$ of the purified DHPS. The focusing procedure was carried out at $4^{\circ} \mathrm{C}$ and according to the manufacturer's instructions included with the apparatus. The gel was developed over $60 \mathrm{~min}$ at a current of $40 \mathrm{~mA}$. Human hemoglobin (Pi 6.8) served as a control for each experiment. Proteins were considered to have reached their isoelectric points when the movement of hemoglobin, which was loaded on separate lanes at either end of the electrophoretic plate, stabilized at parallel positions. After development, the gel was cut into $0.5-\mathrm{cm}$ strips. One-half of each strip was placed into $0.5 \mathrm{ml}$ of deionized water for $\mathrm{pH}$ determination after equilibration at room temperature for $1 \mathrm{~h}$. The remaining portion of the strips were equilibrated over a 3-h period at $4^{\circ} \mathrm{C}$ in a buffered solution containing $50 \mathrm{mM}$ Tris/ $\mathrm{HCl}, \mathrm{pH} 8.3$, and 
5 mM DTT. DHPS activity was then measured using the eluted enzyme according to the described methods (see below) with the exception that the reaction time was increased to $18 \mathrm{~h}$ and performed at $4^{\circ} \mathrm{C}$. The DHPS Pi was determined by comparison of the enzyme activity with a plot of gel $\mathrm{pH}$ versus distance from the anode.

\section{DHPS catalytic assay}

DHPS was assayed using a modification of an assay previously published (16). Assay tubes contained $5 \mathrm{mM} \mathrm{MgCl}, 5 \mathrm{mM}$ DTT, $10 \mu \mathrm{M}$ $\mathrm{H}_{2} \mathrm{PtCH}_{2} \mathrm{OPP}, 1 \mu \mathrm{M}\left[{ }^{3} \mathrm{H}\right.$ ]pABA (final sp act, $2 \mathrm{Ci} / \mathrm{mmol}$ ), and $40 \mathrm{mM}$ Tris/ $\mathrm{HCl}, \mathrm{pH} 8.3$, in a total reaction volume of $100 \mu \mathrm{l}$. Various concentrations of inhibitors were added when applicable. Reactions were initiated by the addition of $0.5 \mathrm{mU}$ of enzyme $(1 \mathrm{U}=1 \mathrm{nmol}$ of product formed $/ \mathrm{min}$ ). After a $30-\mathrm{min}$ incubation at $37^{\circ} \mathrm{C}$ the reaction tubes were placed on ice to terminate the reactions, and then spotted onto $3 \times 30-\mathrm{cm}$ strips of $3 \mathrm{MM}$ chromatography paper (Whatman Laboratory Products Inc.). The strips were developed in a descending chromatography tank using an elution buffer of $0.1 \mathrm{M} \mathrm{KH}_{2} \mathrm{PO}_{4}, \mathrm{pH}$ 7.0. The origins containing the labeled products of the reaction were cut from the strips, placed in scintillation vials, and counted in a liquid scintillation counter (Packard Tri-Carb; Packard Instrument Co. Inc., Downers Grove, IL) $24 \mathrm{~h}$ after the addition of $9.5 \mathrm{ml}$ of counting cocktail (3A70b; Research Products International Corp., Mt. Prospect, IL).

\section{6-Hydroxymethyl-7,8-dihydropterin pyrophosphokinase assay}

Kinase activity was measured as a coupled reaction that included kinase and DHPS activity. The kinase assay was performed in an identical fashion as that for DHPS except: $50 \mathrm{mM}$ ATP was added to the reaction tubes; the substrate was changed to $50 \mu \mathrm{M}$ 6-hydroxymethyl7,8-dihydropterin; and the final pABA concentration was increased to $5 \mu \mathrm{M}$. These reactions were allowed to proceed for $1 \mathrm{~h}$ at $37^{\circ} \mathrm{C}$ to allow adequate conversion of the substrate to the dihydropteroate product.

\section{Protein analysis}

Proteins were quantitated according to the methods of Bradford using BSA as the protein standard (17).

\section{pABA uptake studies}

The potency of the various inhibitors was assessed in intact organisms according to published methods (18). These methods quantitated the ability of drugs to inhibit the metabolism of $\left[{ }^{3} \mathrm{H}\right] \mathrm{pABA}$ to intracellular folates. Briefly, $T$. gondii trophozoites ( $10^{5}$ organisms) were placed into tissue culture flasks containing a monolayer of Wi-38 human lung fibroblast cells and $10 \mathrm{ml}$ of pABA and folate-free RPMI media supplemented with $10 \%$ fetal bovine serum. Plated organisms were treated with various concentrations of the drug under study for $2 \mathrm{~h}$, followed by an 18 -h exposure to $0.6 \mu \mathrm{M}\left[{ }^{3} \mathrm{H}\right] \mathrm{pABA}$ (sp act $50 \mathrm{Ci} / \mathrm{mmol}$ ). At the end of the exposure the cells and organisms were harvested with the aid of a rubber policeman and washed three times with ice-cold PBS. Labeled intraorganism folates were then extracted by a 1-min immersion into boiling water after the addition of $2 \mathrm{ml}$ of boiling $2 \%$ ascorbate, $\mathrm{pH}$ 6.0, and 2\% 2-ME. Cellular debris and denatured protein were then removed by centrifugation for $5 \mathrm{~min}$ at $2,000 \mathrm{~g}$, followed by hydrolase treatment with $1 \mathrm{ml}$ of partially purified hog kidney hydrolase $\left(12-15 \mathrm{mg}\right.$ protein $/ \mathrm{ml}$ ) for $30 \mathrm{~min}$ at $37^{\circ} \mathrm{C}$. Porcine proteins were denatured in boiling water, followed by clarification at $2,000 \mathrm{~g}$ for 5 min. The treated folates were concentrated using a C-18 Sep-Pak (Waters Associates, Milford, MA) and separated by HPLC according to previously described methods (19). The separated folates were quantitated by an in-line liquid scintillation counter (Flow-one Beta, model CR; Radiomatic Instruments \& Chemical Co., Inc., Tampa, FL).

\section{Data analysis}

All kinetic parameters were computed using a nonlinear least squares kinetics program designed by Dr. Rodbard and Dr. Lutz (20) and converted for use on a Macintosh computer. $\mathrm{IC}_{50}$ values for both the intact cell and cell-free experiments were computed using the ALLFIT program on the National Institutes of Health DEC 10 computer system (21), except for the values determined for the sulfone analogues presented in Table $\mathrm{V}$. These $\mathrm{IC}_{50}$ 's were determined by weighted least squares fitting of the pure competitive inhibition equation. Beginning with the usual expression for this type of inhibition,

$$
v=\frac{V}{1+\frac{K}{S}\left(1+\frac{I}{K_{\mathrm{i}}}\right)},
$$

where $v$ is the enzyme reaction rate, $V$ is the maximal rate (this $V$ also includes second substrate terms as long as this substrate has constant concentration), $K$ is the Michaelis constant of the inhibited substrate $(s), K_{\mathrm{i}}$ is the inhibitor constant, and $I$ is the inhibitor concentration. An expression, $A$, for fractional remaining activity in the presence of an inhibitor may be derived from the definition $A=v(I) / v(0)$. Expressed as an inverse,

$A^{-1}=1+\frac{K}{K_{\mathrm{i}}(K+S)} I=1+\beta I$.

For a given sulfone, $\beta$ is a constant since $K_{\mathrm{i}}$ is inhibitor specific, and $S$ (i.e., pABA) is not varied during the course of inhibition measurements. $\beta^{-1}$ is equivalent to the $\mathrm{IC}_{50}$. Because Eq. 1 is linear, a simple regression to this yielded an $\mathrm{IC}_{50}$ for each of the inhibitors investigated.

In performing these regressions, we used a local variance weighting factor proportional to $A^{2}$, a relationship holding under the assumption that the enzyme activities measured both in the presence and absence of inhibitor are characterized by a constant coefficient of variation.

\section{Results}

\section{DHPS preparation}

Purification and stability. Affinity columns of blue and green Sepharose bound the DHPS enzyme with adequate affinity to allow a high degree of purification with high yield when the affinity columns were used sequentially. Table I illustrates a representative purification and Fig. 1 is typical of the elution profile of the enzyme from the green Sepharose column. Elution from the blue and green columns occurred with $\mathrm{KCl}$ concentrations of 0.6 and $0.8 \mathrm{M}$, respectively. Generally, purification resulted in the recovery of 5-10-fold more enzyme activ-

Table I. Affinity Purification of T. gondii DHPS

\begin{tabular}{lcccc}
\hline & Protein & Specific activity & $\begin{array}{c}\text { Fold } \\
\text { purification }\end{array}$ & Yield \\
\hline & $m g / m l$ & pmol/min per $m g$ & & $\%$ \\
$\begin{array}{l}\text { Crude } \\
\text { Blue Sepharose } \\
\text { affinity column }\end{array}$ & 24 & 1.2 & 1 & 100 \\
$\begin{array}{c}\text { Green Sepharose } \\
\text { affinity column }\end{array}$ & 0.34 & 297.5 & 250 & 1,396 \\
\hline
\end{tabular}

Purification scheme for the isolation of DHPS enzyme from a cytosolic preparation of $T$. gondii. The cytosolic fraction from the $T$ gondii organisms was applied to the blue Sepharose column which was developed using a $\mathrm{KCl}$ gradient. The active fractions from the blue affinity column were pooled and concentrated before loading onto the green affinity column, which was also developed using a $\mathrm{KCl}$ gradient. The active fractions collected from the green column with the highest specific activity had protein concentrations $<1 \mu \mathrm{g} / \mathrm{ml}$. 


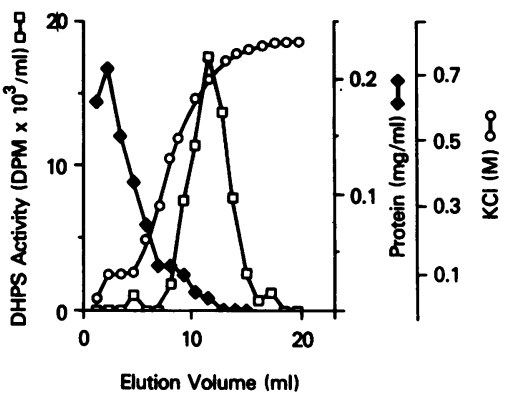

Figure 1. Purification of DHPS by green Sepharose chromatography. The DHPS protein was purified using a green Sepharose dye affinity column. After elution from the prior affinity step, the active fractions were pooled, concentrated by ultrafiltration, and diluted to a final

salt concentration of $<200 \mathrm{mM}$. This preparation was applied to the green Sepharose column preequilibrated with $100 \mathrm{mM} \mathrm{KCl}$ buffer. After washing with 5 column volumes of the loading buffer, the column was developed at room temperature using a linear $\mathrm{KCl}$ gradient. Protein elution (४), DHPS activity ( $($ )), and $\mathrm{KCl}$ gradient (o).

ity than was present in the crude preparations, suggesting the elimination of an inhibitor or enzymatic activity capable of degrading the substrate. In addition, 6-hydroxymethyl-7,8-dihydropterin pyrophosphokinase activity was also assayed and found to copurify with DHPS such that its fold-purification after the final step (green Sepharose) was identical to that of DHPS. This activity was also found in identical fractions as DHPS using an HPLC gel filtration column to measure the molecular weight of the green Sepharose purified enzyme (see below).

While the crude $T$. gondii cytosolic preparations were relatively stable with repeated freeze-thawing, and when stored at $-80^{\circ} \mathrm{C}$, the purified DHPS activity was extremely unstable, having a half-life of only 1-2 d. Because of the limited availability of $T$. gondii DHPS, we conducted preliminary stability experiments with DHPS purified from $E$. coli using the exact methods outlined above. As shown in Table II, we found little effect on DHPS stability with the addition of sucrose or protease inhibitors, or with storage at either 4 or $-80^{\circ} \mathrm{C}$ despite the presence of $2-\mathrm{ME}$ and Tris/ $\mathrm{HCl}$ buffer. However, while the addition of either BSA or DTT alone had little effect, the combination of the two agents resulted in stabilization of enzyme activity. Table II represents the effect of combining DTT, BSA, and 2-ME in a buffered solution on the stability of $T$. gondii DHPS. The combination of these agents resulted in a marked stabilization of the enzyme for at least $14 \mathrm{~d}$. We found that concentrations of BSA of 0.01 or $1 \%$ resulted in identical stabilization. Other potential stabilizers led to no additional improvement when tested in samples stored at $-80^{\circ} \mathrm{C}$ as illustrated in Table II.

Characterization. The kinetic constants of both substrates for the crude and purified DHPS enzyme are shown in Table III. Under the assay conditions used we found the DHPS reaction to be linear for up to $60 \mathrm{~min}$ and up to an enzyme concentration of $20 \mathrm{mU}$. The Michaelis-Menten constant for pABA was found to be highly dependent on the purity of the enzyme with an apparent affinity 10-fold greater for the purified enzyme $(0.36 \mu \mathrm{M})$ when compared with the crude enzyme $(3.6 \mu \mathrm{M})$. The molecular weight of the enzyme in its native state was determined by molecular sizing chromatography using an HPLC system equipped with a protein sizing column capable of separating proteins with molecular weights in the range of $12,000-300,000$. The sizing chromatography revealed the enzymatic activity to elute at a molecular weight of
Table II. Stability of Purified DHPS from E. coli and T. gondii

\begin{tabular}{|c|c|c|c|c|c|}
\hline \multirow[b]{3}{*}{ Addition* } & \multicolumn{5}{|c|}{ Activity remaining (\% initial) } \\
\hline & \multicolumn{5}{|c|}{ Days after purification } \\
\hline & 1 & 2 & 3 & 5 & 9 \\
\hline \multicolumn{6}{|l|}{ E. coli DHPS } \\
\hline None $\left(4^{\circ} \mathrm{C}\right)$ & & 23 & 18 & 11 & \\
\hline None $\left(-80^{\circ} \mathrm{C}\right)$ & & 38 & 5 & 18 & \\
\hline $10 \%$ sucrose & & 23 & $\mathbf{0}$ & 2 & \\
\hline Protease inhibitors ${ }^{\ddagger}$ & & 9 & 3 & 6 & \\
\hline $\mathbf{B S A}^{8}$ & & 35 & 14 & & \\
\hline DTT (5 mM) & & 42 & 18 & & \\
\hline BSA/DTT (5 mM) & & 99 & 58 & 66 & \\
\hline \multicolumn{6}{|l|}{ T. gondii DHPS } \\
\hline None $(0.5 \mathrm{M} \mathrm{KCl})$ & 56 & 28 & & & \\
\hline None (1 M KCl) & 96 & 32 & & & \\
\hline BSA/DTT (5 mM) & 100 & 96 & & 93 & 77 \\
\hline \multicolumn{6}{|l|}{ BSA/DTT ( $5 \mathrm{mM}$ ) plus } \\
\hline DMSO (30\%) & & 96 & & 60 & 70 \\
\hline Ethylene glycol (12\%) & & 85 & & 44 & 53 \\
\hline Triton X-100 (0.02\%) & & 4 & & $\mathbf{0}$ & \\
\hline EDTA (8 mM) & & 72 & & 49 & 49 \\
\hline Protease inhibitors & & 85 & & 79 & 71 \\
\hline $\mathrm{H}_{2} \mathrm{PtCH}_{2} \mathrm{OPP}(10 \mu \mathrm{M})$ & & 79 & & 76 & 76 \\
\hline
\end{tabular}

* All preparations contained Tris/ $\mathrm{HCl}$ (pH 8.3), $100 \mathrm{mM} / 2-\mathrm{ME} 50$ mM.

‡ Soybean trypsin inhibitor $(50 \mu \mathrm{g} / \mathrm{ml})$, chymostatin $(50 \mu \mathrm{g} / \mathrm{ml})$, leupeptin $(20 \mu \mathrm{g} / \mathrm{ml})$, benzamidine $(1 \mathrm{mg} / \mathrm{ml})$, aprotinin $(50 \mu \mathrm{g} / \mathrm{ml})$, and phenanthroline $(2 \mathrm{mg} / \mathrm{ml})$.

${ }^{8}$ Concentrations used were 0.01 and $1 \%$.

125,000 (Fig. $2 A$ ). 6-Hydroxymethyl-7,8-dihydropterin pyrophosphokinase activity was present in the identical fractions as the DHPS activity. Samples of protein from each of the purification steps, including that from the peak activity fractions of the sizing column studies, were applied to $10 \%$ SDS polyacrylamide gels. We noted the consistent appearance of a protein band of $120,000 \mathrm{~mol}$ wt that was not apparent in the crude preparations but that became more intense with the purification process. In addition to this protein band, green column

Table III. Kinetic Parameters of T. gondii DHPS

\begin{tabular}{llc}
\hline & \multicolumn{3}{c}{$K_{\mathrm{m}}$} \\
\cline { 2 - 3 } Substrate & \multicolumn{1}{c}{ Crude } & Purified \\
\hline & & $\mu M$ \\
pABA & $3.6 \pm 0.29$ & $0.36 \pm 0.13$ \\
$\mathrm{H}_{2} \mathrm{PtCH}{ }_{2} \mathrm{OPP}$ & $5.5 \pm 1$ & $5.2 \pm 1.7$ \\
\hline
\end{tabular}

The Michaelis-Menten constants for the substrates were determined for both crude and purified enzyme preparations of $T$. gondii DHPS. The $K_{\mathrm{m}}$ value for the pABA substrate was determined over a range of $0.1-2 \mu \mathrm{M}$ for the purified enzyme and $0.5-10 \mu \mathrm{M}$ for the crude preparation. The pterin substrate was determined over a range of $1-40 \mu \mathrm{M}$. The second substrate was maintained at saturating concentrations. The kinetic values represent the mean and SE of three to six experiments. 
purified protein also contained a consistent protein band at 74,000 and, in three of the six tested preparations, a band of $31,000 \mathrm{~mol} w \mathrm{wt}$. After the molecular sizing chromatography, only the $120,000 \mathrm{~mol} w \mathrm{wt}$ protein remained apparent in the fractions containing DHPS activity. The isoelectric focusing point of the enzyme was found to be 6.3 (Fig. $2 \mathrm{~B}$ ). As shown in Fig. $2 C$, the enzyme retained activity over a broad pH range of 6.0-8.0.

\section{Interaction of DHPS with paraaminobenzoate analogues}

Various sulfonamides, as shown in Table IV, were tested for their ability to inhibit the DHPS enzyme. The sulfonamides varied by over a three log range in $\mathrm{IC}_{50}$ 's with sulfathiazole, sulfamethoxazole, and sulfamethazine being the most potent of the sulfonamides tested. These studies were performed with both crude and purified DHPS. The purified enzyme proved to be more susceptible to inhibition when compared with the crude form by variable degrees depending on the potency of the sulfonamide. This difference was most apparent for the least potent agents, wherein the difference exceeded 40 -fold, and least apparent for the more potent inhibitors ( $<4$-fold). $K_{\mathrm{i}}$ 's were generated for selected inhibitors (Table IV). In all cases tested, the inhibition was found to follow a pure competitive inhibition pattern with respect to pABA. Of interest was the finding that the sulfone, dapsone (4,4'diamino-diphenyl sulfone), was more potent than any of the sulfonamide analogues tested with an $\mathrm{IC}_{50}$ value of 1.2 and $0.25 \mu \mathrm{M}$ for inhibition of the crude and purified enzyme, respectively. Fig. 3 illustrates the competitive nature of inhibition by dapsone and sulfamethoxazole with respect to the pABA substrate.
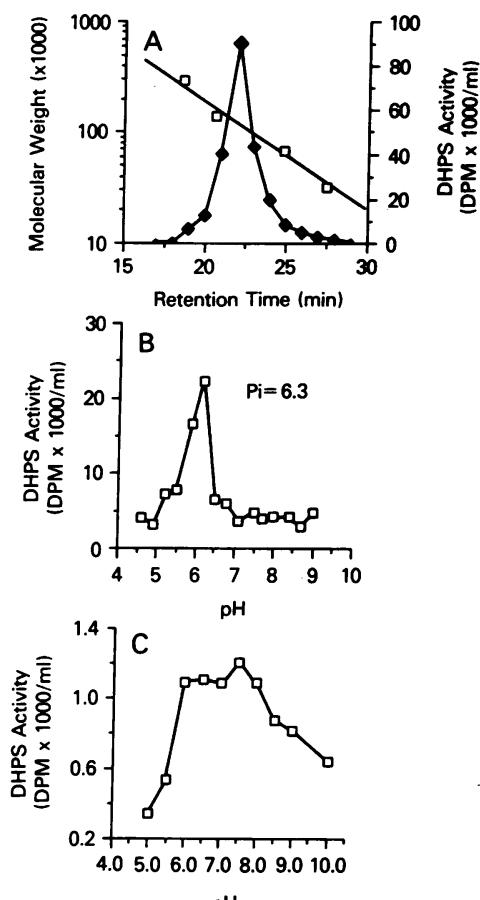
6.1-6.4). The effect of $\mathrm{pH}$ on synthetic function $(C)$ was determined by performing the assay at each of the denoted $\mathrm{pH}$ intervals using $100 \mathrm{mM}$ Tris/HCl buffer. Assay tubes were tested for $\mathrm{pH}$ accuracy after the inclusion of all reactants, including enzyme.
Table IV. Inhibition of T. gondii DHPS by pABA Analogues

\begin{tabular}{|c|c|c|c|}
\hline \multirow[b]{2}{*}{ Drug } & \multicolumn{2}{|c|}{ IC $_{\text {so }}$} & \multirow[b]{2}{*}{$\boldsymbol{K}_{\mathbf{i}}$} \\
\hline & Crude & Pure & \\
\hline & & $\mu M$ & \\
\hline Sulfathiazole & $5.9 \pm 1^{*}$ & $1.7 \pm 0.5$ & $1.9 \pm 1$ \\
\hline Sulfamethoxazole & $14 \pm 3$ & $2.7 \pm 0.7$ & $21 \pm 6$ \\
\hline Sulfamethazine & $7.7 \pm 3$ & $5.7 \pm 2$ & \\
\hline Sulfadiazine & $19 \pm 5$ & $11 \pm 2$ & $19 \pm 5$ \\
\hline Sulfabenzamide & $16 \pm 12$ & $15 \pm 5$ & \\
\hline Sulfamethizole & $94 \pm 40$ & $7.9 \pm 3$ & \\
\hline Sulfisoxazole & $165 \pm 50$ & $17 \pm 6$ & $21 \pm 2$ \\
\hline Sulfapyridine & $280 \pm 132$ & $4.6 \pm 2$ & \\
\hline Sulfamerazine & $324 \pm 40$ & $7.2 \pm 2$ & \\
\hline Sulfacetamide & $495 \pm 151$ & $42 \pm 16$ & \\
\hline Sulfanilamide & $1,365 \pm 652$ & $24 \pm 7$ & $68 \pm 26$ \\
\hline Sulfadoxine & $1,940 \pm 1,090$ & $110 \pm 8$ & \\
\hline Sulfinpyrazone & $>10,000$ & $1,000 \pm 1,300$ & \\
\hline Dapsone & $1.2 \pm 0.03$ & $0.25 \pm 0.08$ & $0.81 \pm 0.4$ \\
\hline
\end{tabular}

* Mean \pm SEM represent two to six separate experiments.

\section{Interaction of DHPS with sulfone analogues}

Because of the strength of dapsone as an inhibitor of DHPS, we investigated the ability of various sulfone analogues to inhibit the DHPS enzyme relative to dapsone. Using the DHPS assay described above with purified enzyme, enzyme activities were determined in the presence of 1 - and $10-\mu \mathrm{M}$ concentrations of various sulfone inhibitors. For the 25 sulfone analogues summarized in Table V, all compounds except AA had at least one of the residual activities lying between 2 and $80 \%$, and nearly half had both activities within this range. The $\mathrm{IC}_{50}$ 's obtained by the data analysis method described previously closely reproduce the experimental activities for all inhibitors examined. Experimental activities were generally within $6 \%$ of theoretical. $\mathrm{The}^{\mathrm{IC}} \mathrm{C}_{50}$ for dapsone was obtained from a separate

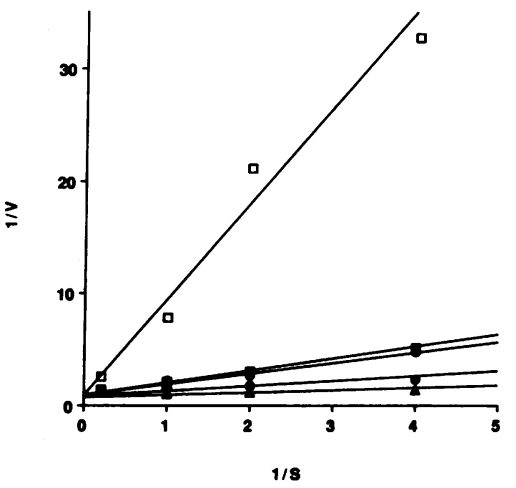

Figure 3. Representative double-reciprocal plots of DHPS inhibition by dapsone and sulfamethoxazole. A representative doublereciprocal plot of the interactions of dapsone and sulfamethoxazole is illustrated. For these experiments, the concentration of the pterin substrate was held constant $(10 \mu \mathrm{M})$ and variable amounts of the

pABA $(0.1-10 \mu \mathrm{M})$ were tested against the concentrations of each inhibitor as noted. $\triangle$, No inhibitor; $0,50 \mu \mathrm{M}$ sulfamethoxazole; $\bullet, 10$ $\mu \mathrm{M}$ sulfamethoxazole; $\boldsymbol{\omega}, 1 \mu \mathrm{M}$ dapsone; $\square, 10 \mu \mathrm{M}$ dapsone. All reactions were initiated with $0.5 \mathrm{mU}$ of the purified DHPS enzyme and allowed to proceed for $30 \mathrm{~min}$ before processing as outlined in Methods. All points represent the mean of duplicate determinations from a representative experiment. $S$, Concentration of $\mathrm{pABA} \times 10^{6}$; $V$, moles of product formed per minute $\times 10^{10}$. 


\begin{tabular}{|c|c|c|c|c|c|c|}
\hline Analogue & $2^{\prime}$ & $3^{\prime}$ & $4^{\prime}$ & $5^{\prime}$ & $6^{\prime}$ & $\begin{array}{l}\text { Potency relative to dapsone } \\
\qquad\left(\log \frac{\mathrm{IC}_{50} \text { dappoose }}{\mathrm{IC}_{50} \text { outrone }}\right)^{*}\end{array}$ \\
\hline A & $\mathrm{CH}_{3}$ & $\mathbf{H}$ & $\mathrm{NH}_{2}$ & $\mathbf{H}$ & $\mathbf{H}$ & -0.910 \\
\hline B & $\mathrm{H}$ & $\mathbf{H}$ & $\mathrm{CH}_{3} \mathrm{CH}_{2} \mathrm{CH}_{2}$ & $\mathbf{H}$ & $\mathbf{H}$ & -1.419 \\
\hline D & $\mathrm{CH}_{3}$ & $\mathbf{H}$ & $\mathbf{H}$ & $\mathbf{H}$ & $\mathbf{H}$ & -1.452 \\
\hline F & $\mathbf{H}$ & $\mathbf{H}$ & AcNH & $\mathbf{H}$ & $\mathbf{H}$ & -1.319 \\
\hline $\mathbf{H}$ & $\mathbf{H}$ & $\mathrm{Cl}$ & $\mathbf{H}$ & $\mathbf{H}$ & $\mathbf{H}$ & -1.385 \\
\hline I & $\mathbf{H}$ & $\mathbf{H}$ & $\mathrm{Cl}$ & $\mathbf{H}$ & $\mathbf{H}$ & -1.265 \\
\hline $\mathbf{J}$ & $\mathbf{H}$ & $\mathbf{H}$ & $\mathrm{CH}_{3}$ & $\mathbf{H}$ & $\mathbf{H}$ & -1.747 \\
\hline $\mathbf{L}$ & $\mathrm{SO}_{2} \mathrm{NHAc}$ & $\mathbf{H}$ & $\mathbf{H}$ & $\mathbf{H}$ & $\mathbf{H}$ & -1.343 \\
\hline $\mathbf{M}$ & $\mathrm{OH}$ & $\mathbf{H}$ & $\mathbf{H}$ & $\mathrm{OH}$ & $\mathbf{H}$ & -0.948 \\
\hline O & $\mathbf{H}$ & $\mathrm{SO}_{2} \mathrm{NH}_{2}$ & $\mathrm{NH}_{2}$ & $\mathbf{H}$ & $\mathbf{H}$ & -0.982 \\
\hline $\mathbf{P}$ & $\mathbf{H}$ & $\mathbf{H}$ & $\mathrm{NHCH}_{2} \mathrm{CH}_{2} \mathrm{OH}$ & $\mathbf{H}$ & $\mathbf{H}$ & -0.531 \\
\hline $\mathbf{S}$ & $\mathbf{H}$ & $\mathrm{Cl}$ & $\mathrm{NH}_{2}$ & $\mathbf{H}$ & $\mathbf{H}$ & -0.157 \\
\hline $\mathrm{T}$ & $\mathbf{H}$ & $\mathrm{NH}_{2}$ & $\mathrm{NH}_{2}$ & $\mathbf{H}$ & $\mathbf{H}$ & -1.866 \\
\hline $\mathrm{U}$ & $\mathbf{H}$ & $\mathbf{H}$ & $\mathrm{Br}$ & $\mathbf{H}$ & $\mathbf{H}$ & -1.898 \\
\hline W & $\mathbf{H}$ & $\mathrm{NH}_{2}$ & $\mathrm{CH}_{3} \mathrm{CH}_{2} \mathrm{OCH}_{2} \mathrm{CH}_{2} \mathrm{NH}$ & $\mathbf{H}$ & $\mathbf{H}$ & -2.017 \\
\hline $\mathbf{X}$ & $\mathbf{H}$ & $\mathbf{H}$ & $\mathrm{CH}_{3} \mathrm{O}\left(\mathrm{CH}_{2}\right)_{3} \mathrm{NH}$ & $\mathbf{H}$ & $\mathbf{H}$ & -0.841 \\
\hline AA & $\mathbf{H}$ & $\mathrm{CH}_{3}$ & $\mathrm{H}$ & $\mathbf{H}$ & $\mathbf{H}$ & -2.314 \\
\hline $\mathrm{EE}$ & $\mathrm{NH}_{2}$ & $\mathbf{H}$ & $\mathrm{SO}_{2} \mathrm{NH}_{2}$ & $\mathbf{H}$ & $\mathbf{H}$ & -1.553 \\
\hline GG & $\mathrm{H}$ & $\mathbf{H}$ & $\mathrm{NH}\left(\mathrm{CH}_{2}\right)_{3} \mathrm{NH}_{2}$ & $\mathbf{H}$ & $\mathbf{H}$ & -1.146 \\
\hline HH & $\mathrm{OH}$ & $\mathbf{H}$ & $\mathrm{NH}_{2}$ & $\mathbf{H}$ & $\mathbf{H}$ & -2.027 \\
\hline II & $\mathrm{NH}_{2} \mathrm{SO}_{2}$ & $\mathbf{H}$ & $\mathrm{NH}_{2} \mathrm{SO}_{2}$ & $\mathbf{H}$ & $\mathbf{H}$ & -1.710 \\
\hline JJ & $\mathbf{H}$ & $\mathrm{CH}_{3}$ & $\mathrm{NH}_{2}$ & $\mathbf{H}$ & $\mathbf{H}$ & -1.199 \\
\hline KK & $\mathbf{H}$ & $\mathrm{NH}_{2}$ & $\mathbf{H}$ & $\mathbf{H}$ & $\mathbf{H}$ & -1.613 \\
\hline MM & $\mathbf{H}$ & $\mathrm{SO}_{3} \mathrm{H}$ & $\mathrm{NH}_{2}$ & $\mathbf{H}$ & $\mathbf{H}$ & -1.411 \\
\hline NN & $\mathbf{H}$ & $\mathrm{SO}_{2} \mathrm{NHAc}$ & $\mathrm{NH}_{2}$ & $\mathbf{H}$ & $\mathbf{H}$ & -0.949 \\
\hline Dapsone & $\mathbf{H}$ & $\mathrm{H}$ & $\mathrm{NH}_{2}$ & $\mathbf{H}$ & $\mathbf{H}$ & 0.000 \\
\hline
\end{tabular}

$*-\log \mathrm{IC}_{50 \text { dapsone }}=0.6021$ ( $\mathrm{IC}_{50}$ in micromolar units).

set of experiments using five inhibitor concentrations and was found to be $0.25 \mu \mathrm{M}$.

Potencies of the various sulfone inhibitors relative to dapsone were defined as

$\log \left(\mathrm{IC}_{50 \text { dapsone }} / \mathrm{IC}_{50}\right.$ sulfone $)$,

and are listed in Table V. By this definition, the stronger sulfone inhibitors are characterized by more positive potencies. Thus, the strongest inhibitors found among the 25 tested were the $3^{\prime}-\mathrm{Cl}$ derivative (compound $\mathrm{S}$ ) and the 4'-aminoethanol derivative (compound $\mathrm{P}$ ). Compound $\mathrm{S}$ has a potency similar to dapsone, while compound $P$ is slightly less inhibiting. No compounds tested exhibited greater mean inhibitory potential than dapsone when tested against purified enzyme.

To ascertain whether high potency sulfones exist bearing combinations of substituents other than those investigated experimentally, we also performed a quantitative structure-activity analysis of the data using the Fujita-Ban model (22-24). This technique yields the contribution of each substituent group to sulfone potency and, once such group contributions are in hand, the positive ones may then be arbitrarily summed to identify new compounds that are likely to exhibit high overall potency.

This analysis showed that all best-estimate group contributions to potency were negative quantities, i.e., these substituents, either alone or in arbitrary combination with others, are unlikely to yield analogues that are substantially better inhibitors of purified DHPS than is dapsone itself. $(\mathrm{OH}$ substituents are excluded from this finding since the $\mathrm{pH}$ used in the DHPS assay alters the charge state of these groups from that encountered intracellularly $[25,26]$.)

\section{Metabolic studies using $\left[{ }^{3} \mathrm{H}\right] p A B A$}

In addition to direct enzymatic inhibition in cell-free preparations, we felt it critical to assess the potency of the inhibitors in intact organisms. A variety of factors may alter the effectiveness of a given compound in intact cells including compound stability under physiologic conditions, membrane transport, and intracellular metabolism. We used the ability of the intact organisms to incorporate radiolabeled pABA into their folate pools as a measure of the antifolate's effect on cellular metabolism according to methods previously described in detail (18). 
The results of these studies are illustrated in Fig. 4 for selected DHPS inhibitors. Also shown for comparative purposes are the results using the DHFR inhibitors trimetrexate and pyrimethamine. In general, the inhibitory potency of the DHPS inhibitors in the intact cell assay closely paralleled the findings in the cell-free experiments. The DHFR inhibitor trimetrexate was found to be a potent inhibitor of toxoplasma metabolism with an $\mathrm{IC}_{50}$ of $3.5 \mathrm{nM}$. Pyrimethamine, the inhibitor currently used to treat $T$. gondii infections, was $>200$-fold less potent than trimetrexate. Methotrexate, which requires an active transmembrane transport system not found in toxoplasma organisms, had no metabolic effects at concentrations $>10$ $\mu \mathrm{M}$ (data not shown). These results are in concert with those previously reported using the DHFR inhibitors in cell-free enzymatic studies. The inhibitory potency of three sulfonamides and dapsone in the intact cell assay are also illustrated in Fig. 4. Unlike the cell-free experiments, sulfadiazine and sulfamethoxazole appeared to be two- to threefold better inhibitors than dapsone. Finally, since there was a great dependence of substrate and inhibitor affinity on the purity of the enzyme, we compared the inhibitory results of selected sulfonamide and sulfone inhibitors when their potency was assayed using each of the three assay systems described in this report (Table VI). When the inhibitory potency of these inhibitors was compared, we noted that the cell-free results using the crude enzyme provided a more accurate quantitative indication of inhibitory potency when either cell-free result was compared with the intact cell system. From a qualitative perspective, either set of cell-free data accurately predicted the relative inhibitory potency of the inhibitors in intact cells. The sulfone analogues, $S$ and $P$, demonstrated similar potency in the intact and cell-free assay systems. In particular, analogue $S$ was fivefold more potent than dapsone and twofold more potent than even the most potent sulfonamides in the intact cell assay system.

\section{Discussion}

We report here a novel, high-yield, and simple purification scheme capable of purifications of $T$. gondii DHPS $>30,000$ fold. The initial characterization of the $T$. gondii enzyme revealed it to be a $125,000 \mathrm{~mol}$ wt protein (native state), which is intermediate between that reported for $E$. coli $(50,000)$ and plasmodia $(190,000-250,000)(27-29)$. Given the copurifica-

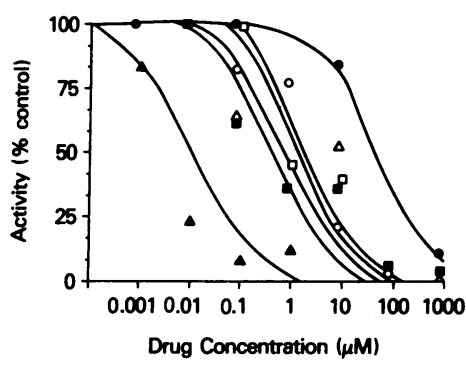

Figure 4. Inhibition of intact $T$. gondii organisms by antifolates. Various antifolates were tested as metabolic inhibitors of intact $T$. gondii organisms. $\triangle$, Trimetrexate; $n$, sulfamethoxazole; $\square$, pyrimethamine; $\circ$, dapsone; •, sulfisoxazole; $\Delta$, sulfadiazine. In each case, the organisms were exposed to various concentrations of the inhibitors for $2 \mathrm{~h}$ before the addition of radiolabeled pABA. After an additional $18 \mathrm{~h}$ the organisms were harvested and their intracellular folates quantitated. These values served as a measure of the inhibitory potency of the inhibitors when total intracellular folates were compared with those in control organisms $(100 \%)$. Each point represents the mean of three to six independent experiments.
Table VI. Comparison of Selected Inhibitors in the Three Study Systems

\begin{tabular}{lccc}
\hline & \multicolumn{3}{c}{ IC $_{s_{0}}$} \\
\cline { 2 - 4 } \multicolumn{1}{c}{ Inhibitor } & Crude DHPS & Pure DHPS & Intact cells \\
\hline & & $\mu M$ & \\
Sulfonamides & & & \\
Sulfathiazole & $5.9 \pm 1^{*}$ & $1.7 \pm 0.5$ & $0.88 \pm 0.4$ \\
Sulfamethoxazole & $14 \pm 3$ & $2.7 \pm 1$ & $0.88 \pm 0.1$ \\
Sulfadiazine & $19 \pm 5$ & $11 \pm 2$ & $1.5 \pm 0.3$ \\
Sulfisoxazole & $164 \pm 50$ & $18 \pm 6$ & $57 \pm 9$ \\
Sulfanilamide & $1,365 \pm 652$ & $24 \pm 7$ & $>1,000$ \\
Sulfones & & & \\
Dapsone & $1.2 \pm 0.03$ & $0.25 \pm 0.08$ & $2.4 \pm 0.2$ \\
S & $1.1 \pm 0.5$ & $0.35 \pm 0.08$ & $0.47 \pm 0.2$ \\
P & $1.2 \pm 0.5$ & $0.81 \pm 0.2$ & $2.1 \pm 0.9$ \\
& & & \\
\hline
\end{tabular}

* Mean \pm SEM represent four to eight separate experiments using five inhibitor concentrations for each of the three study systems.

tion of 6-hydroxymethyl-7,8-dihydropterin pyrophosphokinase activity, which also appeared in identical fractions throughout the purification scheme as the DHPS activity, it is conceivable either that both activities reside on the same protein or that the protein is comprised of separate subunits with distinct functions. Richey and Brown were able to resolve the DHPS and 6-hydroxymethyl-7,8-dihydropterin pyrophosphokinase activities in $E$. coli into proteins with $M_{\mathrm{r}}$ 's of 50,000 (DHPS) and 15,000 (dihydropterin pyrophosphokinase) using a Sephadex G-100 column (27). While DHPS activity was also separable from 6-hydroxymethyl-7,8-dihydropterin pyrophosphokinase activity by DEAE-Sephadex chromatography in Plasmodium berghei, these activities were not separable in Plasmodium chabaudi, nor were they separable in pea seedlings $(16,30,31)$. DHPS protein purified through the green Sepharose affinity column did not appear to be homogeneous, as at least one additional protein $(74,000 \mathrm{~mol} \mathrm{wt})$ was consistently noted to copurify. DHPS further purified by sizing chromatography contained both synthase and pyrophosphokinase activity and appeared as a single protein band on a silverstained denaturing polyacrylamide gel.

As reported by others, we also noted increased enzymatic yield (up to 10-fold) during purification. This apparent increase in activity may be explained by the presence of enzymatic activity in the crude preparations capable of degrading the substrate. Upon examination of the crude preparations, we identified enzymatic activity capable of degrading a diphosphate (ADP) that was not present after the first purification step (data not shown). Whether this activity is capable of degrading the pyrophosphate substrate remains to be elucidated. Purification of DHPS from potential inhibitors present in the crude preparations represents an additional possibility that has not been excluded. Instability of the DHPS enzymatic activity isolated from other organisms has not previously been noted and may be due to differences in the purity or source of the preparations used in other studies $(16,27-30)$. The DHPS activity in crude cytosolic preparations of $T$. gondii was stable and became unstable only with purification $>100-200$-fold. The purified enzyme appears to be highly susceptible to oxidation and adherence to inert surfaces given the stability of- 
fered by an inclusion of DTT and BSA. The DHPS enzyme was found to have an acidic Pi of 6.3. and was capable of maintaining catalytic activity over a broad $\mathrm{pH}$ range. Previous reports have noted that the optimum $\mathrm{pH}$ for plastic enzyme is $\sim 8.5(29,30)$, and this is consistent with that noted for $T$. gondii.

In investigating the Michaelis-Menten constants for the DHPS enzyme with respect to both substrates, we found the affinity constant for pABA to be similar to those reported for enzymes isolated from both $P$. berghei $(0.28 \mu \mathrm{M})$ and $E$. coli $(0.21 \mu \mathrm{M})$ by Ferone and co-workers $(16,28)$, but somewhat tighter than that reported by others $(1.1-2.8 \mu \mathrm{M})(29,30)$. These differences may relate to the dependence of affinity on the purity of the enzyme preparation. We found that the $K_{\mathrm{m}}$ for $\mathrm{pABA}$ differed by a factor of 10 between crude and pure enzyme, while the $K_{\mathrm{m}}$ for the pterine substrate showed little dependence on the purity of the enzyme. The affinity of $T$. gondii DHPS for the pterin pyrophosphate substrate is slightly weaker $(\sim 5 \mu \mathrm{M})$ than that reported for either $P$. berghei or $E$. coli $(0.5-1.4 \mu \mathrm{M})(16,28)$.

These kinetic studies allow only speculation as to why the substrate and inhibitor affinities are dependent on enzyme purity. It is plausible that the conformation of the enzyme changes with purification to allow greater access to the active site and thereby enhance the apparent affinity of the substrates for the enzyme. This postulate is additionally supported by the finding that the potency of various inhibitors depended on the enzyme purity. This difference was most apparent for the weaker inhibitors but is, in general, apparent even for the most potent compounds including the sulfones. This postulate would account for the crude enzyme being a better predictor of inhibitory activity in intact cells, as the enzyme in the crude preparations may more closely reflect the native conformation in intact cells.

The inhibition of DHPS isolated from bacterial and plasmodial sources by sulfonamides and sulfones and their utility as therapeutic agents has previously been reported $(16,28,29)$. Investigations of the interactions of sulfonamides and sulfones with the DHPS isolated from $T$. gondii demonstrated that the sulfonamides exhibited a broad range of inhibitory potency, with sulfadiazine, the DHPS inhibitor of choice for the treatment of toxoplasma encephalitis, being one of the most potent of the sulfonamides tested. Of some note was the finding that sulfadoxine, commonly used in prophylaxis regimens for Pneumocystis carinii, was a particularly poor toxoplasma DHPS inhibitor. These results are in conformity with those reported from in vivo experiments using the acute murine toxoplasma model. In the murine model, sulfadiazine, sulfamethazine, sulfamerazine, and sulfathiazole were noted to be of high potency, while sulfisoxazole, sulfapyridine, and sulfanilamide were found to be therapeutically poor compounds (9-12). As others have previously reported using DHPS from $E$. coli and Plasmodia, we found both classes of inhibitors to be purely competitive with respect to the pABA substrate (16). A finding that was in contrast with previously reported bacterial studies but consistent with results from the murine model, was the potency of the sulfone, dapsone, relative to the sulfonamides. Generally, the sulfones have been found to be relatively poor inhibitors of bacterial DHPS. These studies suggest that the $T$. gondii enzyme is substantially different from that of bacteria in its interaction with these agents and thus probably distinct in its overall protein structure.

Several investigators have noted that the potency of the sulfonamides may be directly related to their ability to ionize at physiologic $\mathrm{pH}(32-34)$. Since these drugs penetrate cellular membranes with difficulty, the best inhibitors of intact organisms were those that were half-ionized at physiologic $\mathrm{pH}$, i.e., their $\mathrm{pK}_{\mathrm{a}}$ was between 6 and 7.4. The nature of the sulfone structure does not allow these compounds to be fit into a similar relationship; however, the activity of these compounds as inhibitors of bacterial growth has been related to the molecular charge distribution of the inhibitor with respect to the natural substrate (pABA). De Benedetti and co-workers investigated such structure-activity relationships for the sulfones and identified several analogues with activity exceeding that of dapsone (25). Given the potency of dapsone as an inhibitor of $T$. gondii DHPS, we studied additional sulfone analogues for inhibitory potency. Direct determination of the activity of the sulfones in Table $\mathrm{V}$ against purified DHPS identified compounds $S$ and $P$ as those most similar to dapsone. Quantitative structure-activity analyses then identified the contributions to inhibitory potency from individual substituent groups in the analogues investigated. In the mean, none of these groups were found to contribute positively to potency, and thus no strong candidates for new analogues could be suggested.

Examination of the error factors associated with the various group contributions did reveal the possibility that the $3^{\prime}-\mathrm{Cl}, 4^{\prime}-\mathrm{NH}\left(\mathrm{CH}_{2}\right)_{2} \mathrm{OH}, 2^{\prime}-\mathrm{NH}_{2}$, and $\mathrm{SO}_{2} \mathrm{NH}_{2} / \mathrm{SO}_{2} \mathrm{NHAc}$ groups could be associated with increased potency. Indeed, detailed examination of compound $S$ in the cell-free system led to a statistically insignificant difference in activity from dapsone, leaving open the possibility of its $3^{\prime}-\mathrm{Cl}$ group being inhibition enhancing. In contrast, the $4^{\prime}-\mathrm{NH}\left(\mathrm{CH}_{2}\right)_{2} \mathrm{OH}$ group, characteristic of compound $\mathrm{P}$ and quite similar to the $4^{\prime}$ group of compound $\mathrm{W}$, failed to significantly enhance the activity of dapsone. The $2^{\prime}-\mathrm{NH}_{2}$ group, when it is the only additional substituent on dapsone, has not been investigated in our assay. However, De Benedetti et al. (25), in presenting the activity of sulfones against the DHPS from $E$. coli, reported the $2^{\prime}-\mathrm{NH}_{2}$ derivative of dapsone to be twice as active as the parent compound. It is consistent with our structure-activity analysis that this level of increased activity may also exist against $T$. gondii DHPS, and further testing, perhaps involving the $2^{\prime}, 4^{\prime}, 6^{\prime}$ $\left(\mathrm{NH}_{2}\right)_{3}$ compound as well, is warranted.

To further enhance our understanding of the interactions of pABA analogues with $T$. gondii DHPS, we investigated their effects on intact organisms using the metabolism of radiolabeled $\mathrm{pABA}$ as a measure of inhibitor potency. Unlike the cell-free experiments, this system accounts for events in addition to enzyme inhibition, including inhibitor stability, membrane transport, and intracellular metabolism. We found an excellent quantitative and qualitative relation between the results obtained in the cell-free system and those from the pABA experiments, suggesting that enzyme inhibitor interactions are the critical rate-limiting step for these compounds. Interestingly, the cell-free results using crude enzyme correlated most closely with those obtained from the intact cell experiments when compared with those with purified DHPS, suggesting once again that purification may alter the native state of the enzyme. While compound $S$ had the same potency as dapsone in the cell-free systems, it was fivefold more potent in the intact cell experiments, suggesting an advantage perhaps due to improved membrane transport. The results obtained using DHFR inhibitors, particularly trimetrexate, illustrate the extraordinary potency of these compounds compared with DHPS inhibitors in this assay system. These results document 
the presence of the DHPS enzyme in $T$. gondii organisms and show that it is kinetically distinct from the DHPS of other sources. While we have been able to purify and characterize the enzyme, it appears that kinetic experiments with crude enzyme preparations are quantitatively more representative of the potency that may be expected from pABA analogues in intact organisms. Of importance is the demonstration that sulfonamides vary in potency by over three orders of magnitude, supporting the utility of direct enzyme studies in guiding the selection of sulfonamides for clinical testing. Further, the finding that dapsone and several analogues are highly potent inhibitors of $T$. gondii DHPS supports the consideration of therapeutic trials using dapsone for the treatment of $T$. gondii infections and serves as a focal point for the identification and design of new pABA analogues that may potentially have improved physical, pharmacokinetic, and therapeutic properties.

\section{Acknowledgments}

The authors wish to acknowledge Dr. Robert Ferone for his helpful suggestions regarding this work.

\section{References}

1. Masur, H. 1985. Toxoplasmosis. In Cecil Textbook of Medicine J. P. Wyngaarden and L. H. Smith, editors. W. B. Saunders Company, Philadelphia. 1792-1795.

2. McCabe, R., and J. S. Remington. 1988. Toxoplasmosis: the time has come. N. Engl. J. Med. 318:313-315.

3. Allegra, C. J., J. A. Kovacs, J. C. Drake, J. C. Swan, B. A. Chabner, and H. Masur. 1987. Potent in vitro and in vivo antitoxoplasma activity of the lipid-soluble antifolate trimetrexate. J. Clin. Invest. 79:478-482.

4. Eyles, D. E., and N. Coleman. 1955. An evaluation of the curative effects of pyrimethamine and sulfadiazine alone and in combination on experimental mouse toxoplasmosis. Antibiot. Chemother. (Basel). 5:529-539.

5. Kovacs, J. A., J. W. Heimenz, A. M. Macher, D. Stover, H. W. Murray, J. Shelhamer, H. C. Lane, C. Urmacher, C. Honig, D. L. Longo, M. M. Parker, C. Natanson, J. E. Parrillo, A. S. Fauci, P. A. Pizzo, and H. Masur. 1984. Pneumocystis pneumonia carinii: a comparison between patients with the acquired immunodeficiency syndrome and patients with other immunodeficiencies. Ann. Intern. Med. 100:663-671.

6. Leport, C., F. Raffi, S. Matheron, C. Katlama, B. Regnier, A. Samoit, C. Marche, C. Vedrenne, and J. L. Vilde. 1988. Treatment of central nervous system toxoplasmosis with pyrimethamine/sulfadizine combination in 35 patients with the acquired immuno-deficiency syndrome. Am. J. Med. 84:94-100.

7. Sabin, A. B., and J. Warren. 1942. Therapeutic effectiveness of certain sulfonamides on infection by an intracellular protozoan (toxoplasma). Proc. Soc. Exp. Biol. Med. 51:19-23.

8. Biocca, E., and R. Pasqualin. 1942. Açao terapeutica de alguns compostos sulfa-nil amidicos na infeçao experimental per toxoplasma. Arq. Biol. (Sao Paulo). 26:107-109.

9. Eyles, D. E., and N. Coleman. 1953. The relative activity of the common sulfonamides against experimental toxoplasmosis in the mouse. Am. J. Trop. Med. Hyg. 2:54-63.

10. Eyles, D. E. 1953. The present status of the chemotherapy of toxoplasmosis. Am. J. Trop. Med. Hyg. 2:429-444.

11. Eyles, D. E. 1956. Newer knowledge of the chemotherapy of toxoplasmosis. Ann. NY Acad. Sci. 64:252-267.

12. Eyles, D. E., and N. Coleman. 1955. The effect of sulfadimetine, sulfisoxazole, and sulfapyrazine against mouse toxoplasmosis. Antibiot. Chemother. (Basel). 5:525-528.

13. Eyles, D. E., and N. Coleman. 1957. An evaluation of the effect of sulfones on experimental toxoplasmosis in the mouse. Antibiot. Chemother. (Basel). 7:577-585.

14. Shiota, T., M. N. Disraely, and M. P. McCann. 1964. The enzymatic synthesis of folate-like compounds from hydroxymethylpteridine pyrophosphate. J. Biol. Chem. 239:2259-2266.

15. Weber, K., J. R. Pringle, and M. Osborn. 1972. Measurement of molecular weights by electrophoresis on SDS-acrylamide gel. Methods Enzymol. 26:3-27.

16. Ferone, R. 1973. Enzymatic synthesis of dihydropteroate and dihydrofolate by plasmodium berghei. J. Protozool. 20:459-464.

17. Bradford, M. 1976. A rapid and sensitive method for the quantitation of microgram quantities of protein utilizing the principle of protein-dye binding. Anal. Biochem. 72:248-254.

18. Kovacs, J. A., C. J. Allegra, J. Beaver, D. Boarman, M. Lewis, J. E. Parrillo, B. A. Chabner, and H. Masur. 1989. Characterization of de novo folate synthesis in Pneumocystis carinii and Toxoplasma gondii: potential utilization for screening therapeutic agents. $J$. Infect. Dis. 160:312-320.

19. Allegra, C. J., R. L. Fine, J. C. Drake, and B. A. Chabner. 1986. The effect of methotrexate on intracellular folate pools in human MCF-7 breast cancer cells: evidence for direct inhibition of purine synthesis. J. Biol. Chem. 261:6478-6485.

20. Allegra, C. J., B. A. Chabner, J. C. Drake, R. Lutz, D. Rodbard, and J. Jolivet. 1985. Enhanced inhibition of thymidylate synthase by methotrexate polyglutamates. J. Biol. Chem. 260:9720-9726.

21. DeLean, A., P. J. Munson, and D. Rodbard. 1978. Simultaneous analysis of families of sigmoidal curves: application to bioassay, radioligand assay, and physiological dose-response curves. Am. J. Physiol. 235:E97-E102.

22. Fujita, T., and T. Ban. 1971. Structure-activity study of phenethylamines as substrates of biosynthetic enzymes of sympathetic transmitters. J. Med. Chem. 14:148-152.

23. Kubinyi, H. 1977. Quantitative structure-activity relationships. Arzneim. Forsch. 27:750-758.

24. Free, S. M., Jr., and J. W. Wilson. 1964. A mathematical contribution to structure-activity studies. J. Med. Chem. 7:395-399.

25. De Benedetti, P. G., D. Iarossi, C. Menaizni, V. Caiolfa, C. Frassineti, and C. Cennamo. 1987. Quantitative structure-activity analysis in dihydropteroate synthase inhibition by sulfones: comparison with sulfonamides. J. Med. Chem. 30:459-464.

26. Seydel, J. K., and K. Schaper. 1980. Enzyme Inhibitors as Drugs. M. Sandler, editor. Macmillan Journals Ltd., London. 68.

27. Richey, D. P., and G. M. Brown. 1969. Biosynthesis of folic acid. IX. Purification and properties of the enzymes required for the formation of dihydropteroic acid. J. Biol. Chem. 244:1582-1592.

28. Roland, S., R. Ferone, R. J. Harvey, V. L. Styles, and R. W. Morrison. 1979. Characteristics and significance of sulfonamides as substrates for Escherichia coli dihydropteroate synthase. J. Biol. Chem. 254:10337-10345.

29. McCullough, J., and T. A. Maren. 1974. Dihydropteroate synthetase from Plasmodium berghei: isolation, properties, and inhibition by dapsone and sulfadiazine. Mol. Pharmacol. 10:140-145.

30. Walter, R. D., and E. Konigk. 1974. Purification and properties of the 7,8 dihydropteroate synthesizing enzyme from Plasmodium chabaudi. Z. Phys. Chem. 335:431-437.

31. Okinaka, O., and K. Iwai. 1970. The biosynthesis of folic acid compounds in plants. IV. Purification and properties of the dihydropteroate-synthesizing enzyme from pea seedlings. J. Vitaminol. (Kyoto). 16:201-209.

32. Schmelkes, F. C., O. Wyss, H. C. Marks, B. J. Ludwig, and F. B. Stranskov. 1942. Mechanism of sulfonamide action. I. Acidic dissociation and antibacterial effect. Proc. Soc. Ex. Biol. Med. 50:145-148.

33. Bell, P. H., and R. O. Roblin, Jr. 1942. Studies in chemotherapy. VII. A theory of the relation of structure to activity of sulfanilamide type compounds. J. Am. Chem. Soc. 64:2905-2917.

34. Yamazaki, M., N. Kakeya, T. Morishita, A. Kamada, and A. Aoki. 1970. Biological activity of drugs. X. Relation of structure to the bacteriostatic activity of sulfonamides (1). Chem. Pharm. Bull. (Tokyo). 18:702-707. 